\title{
A cross sectional survey of adherence, perceived efficacy and side effects of methylphenidate among children at a teaching hospital in Sri Lanka
}

\author{
G Jayamaha, WMTM Perera, TA Herath, A Rodrigo
}

\section{Introduction}

Attention deficit hyperactivity disorder (ADHD) is the most commonly diagnosed psychiatric condition in childhood, which if untreated may have a negative effect on education, peer relationships and family disharmony. Methylphenidate is an effective treatment for ADHD, although its use is limited by poor compliance and side effects. Studies on effects of side effects on efficacy, and adherence of methylphenidate in developing countries are scarce.

\section{Methods}

We assessed the adherence, efficacy, and side effects of methylphenidate in children and adolescents treated at a child and adolescent psychiatry clinic of North Colombo Teaching Hospital, Ragama. We gathered information from guardians of the children treated with methylphenidate for at least 2 months, using an interviewer administered questionnaire.

\section{Results}

Among the 149 participants, a majority were males and the mean age of the population was 10.4 years. More than $52 \%$ participants reported $100 \%$ compliance with methylphenidate, but only $12 \%$ complied with non-pharmacological therapies. While $75 \%$ believed the medication to be effective, only $17 \%$ perceived psychosocial strategies to be useful. Poor appetite (44\%) was the most common side effect of methylphenidate and $43 \%$ did not report any side effect. There was a negative correlation between compliance with methylphenidate and the occurrence of poor appetite, as well as with not increasing the initial dose.

\section{Discussion}

The results of this study suggest that methylphenidate is an effective and well-tolerated treatment for children in Sri Lanka with ADHD.

SL J Psychiatry 2018; 9(2): 14-17

\section{Introduction}

Attention deficit hyperactivity disorder (ADHD) is the most commonly diagnosed psychiatry condition in childhood with a global life time prevalence of 8 to $12 \%$ (1). The prevalence of ADHD among children attending the accident service of Lady Ridgeway Hospital in Sri Lanka has been reported to be $18 \%$ (2). ADHD is characterised by hyperactivity, inattention and impulsiveness, and if untreated may lead to adverse effects on education, poor relationships with siblings, peers and neighbors and marital disharmony of parents. It commonly co-occurs with conduct disorder, oppositional defiant disorder, tic disorders, learning disabilities and obsessive-compulsive disorder $(3,4)$.

Treatment for ADHD includes pharmacological, psychosocial and combined therapies. Pharmacotherapy, and psychostimulants in particular is considered the firstline treatment for ADHD in children and adolescents. The effectiveness of psychostimulants is clearly established in ADHD, with a response rate over 75\% (5). Benefits of medication include improvement of symptoms, academic achievement and quality of life (6,7). The improvement related to psychostimulants is reported to be maintained even after 8 years $(5,8)$. Contrary to the abuse and addiction potential of stimulants, long-term studies demonstrate that children treated with psychostimulants do not show increased risk of substance abuse, but in contrast have a reduced risk of abuse of all the psychoactive substances in adolescence and adulthood (9). In spite of proven efficacy and safety, adherence to psychostimulants remains low, with rates of adherence ranging between $52 \%$ to $86 \%$ over a one-year period, and 52 to $65 \%$ over a three-year period (10-12). A reason for the poor

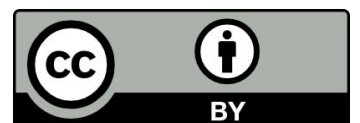

This is an open-access article distributed under the terms of the Creative Commons Attribution 4.0 nternational License, which permits unrestricted use, distribution and reproduction in any medium provided the original author and source are credited. 
adherence is side effects due to psychostimulants, which include reduction of appetite, poor sleep, stomachache, headache, irritability, tics and increases in heart rate and blood pressure (13). Charach et al., report that the mere presence of side effect does not result in discontinuation, but the unacceptable nature of side effect will lead to noncompliance of psychostimulants [14].

Studies on the efficacy, adherence and side effects of methylphenidate in developing countries are scarce. To the best of our knowledge, no such study has been conducted in Sri Lanka. Because of ethno-pharmacology, people of different ethnicities may react differently to medication. Therefore in this study, we explore the adherence, efficacy, and side effects of methylphenidate among children treated at the child and adolescent psychiatry clinic of North Colombo Teaching Hospital, Ragama, Sri Lanka.

\section{Methods}

Children and adolescents aged between 5 years and 18 years, who had been treated with methylphenidate for at least 2 months previously were recruited for the study. We invited all eligible children and adolescents treated at the child and adolescent psychiatry clinic of North Colombo Teaching Hospital, Ragama between Feb 2017 and Jan 2018, to participate in the study. Children whose guardians were unable to provide the necessary information were excluded from the study.

Information on demographics, details of the illness, as well as adherence, efficacy and side effects of methylphenidate were gathered from the guardians using a specially designed and pilot tested interviewer administered questionnaire. Medication adherence was assessed only for a period of 2 months, while side effects occurring from the start of medication prescription were considered. Relevant information was collected by interviewing guardians who attended the clinic with the children or adolescents concerned. Only those who gave written informed consent were included in the study. When necessary and appropriate, information was gathered from children and adolescents, with their consent, in the presence of the guardian. The study was conducted between February 2017 and January 2018.

Data was analysed using the Statistical Package for the Social Sciences (SPSS) version 20. Ethics approval for the study was obtained from the Ethics Review Committee of Faculty of Medicine, University of Kelaniya.

\section{Results}

We approached 173 eligible participants, of whom 150 consented to participate in the study. Of these participants, one had to be excluded subsequently, due incomplete provision of information. Among the 149 participants, a majority were males and mean age of the population was 10.4 years. Demographic and clinical details of the participants are described in table 1 .

\begin{tabular}{|lrc|}
$\begin{array}{l}\text { Table 1. Demographic and clinical characteristics } \\
\text { of participants }\end{array}$ & $\mathrm{N}$ \\
\hline & & \\
Gender & 108 & 72.4 \\
Male & 41 & 27.5 \\
Female & & \\
& & \\
Age & 69 & 46.3 \\
5-9 & 54 & 36.2 \\
10-14 & 26 & 17.4 \\
15-18 & & \\
& & \\
Comorbid diagnosis & 111 & 74.5 \\
Without comorbid diagnosis & 12 & 8.1 \\
Conduct disorder & 26 & 17.4 \\
Learning disability / difficulty & & \\
\hline
\end{tabular}

Psychostimulant medication compliance was satisfactory, with more than $52 \%(\mathrm{n}=78)$ participants reporting $100 \%$ compliance, but only $12 \%(n=18)$ followed psychosocial treatment strategies regularly. Nearly one third of participants (32\%) were treated with an adjunct medication, most commonly risperidone. While $75 \%(n=114)$ believed the medication to be effective, only $17 \%(n=25)$ perceived psychosocial strategies to be useful. Fortyone guardians (28\%) reported psychosocial interventions to be ineffective and difficult to implement. The perceived effectiveness of methylphenidate was low when ADHD was comorbid with conduct disorder and learning disability.

Poor appetite (44\%) was the most common side effect of methylphenidate, followed by headache (20\%), abdominal pain (14\%), irritability (13\%) and poor sleep (7\%). Sixty-four participants (43\%) did not report any side effect due to psychostimulants.

There was a negative correlation between compliance with methylphenidate and the occurrence of poor appetite $(\mathrm{r}=0.390, \mathrm{p}=0.003)$, as well as not increasing the initial dose $(r=0.231, p=0.001)$. There was no significant association between methylphenidate compliance and age, gender or comorbid diagnosis.

\section{Discussion}

The population in this study had a higher treatment compliance when compared to previous international studies (10-12). This may at least partly be explained by 
the relatively short period of time being studied. It is possible that cultural factors, such as the higher level of trust placed in doctors and the greater emphasis given for educational attainment, may have played a role in the relatively higher compliance rates seen in this study. Further, Berger et al., report that adherence to methylphenidate is primarily determined by attitudes toward methylphenidate, which in turn is predominantly influenced by the prescriber's explanation (15). This further supports the possibility that higher rates of adherence to methylphenidate in our study population may also be due to the trust placed in the explanation provided by doctors at the clinic.

We found methylphenidate to be effective for ADHD among the Sri Lankan children in this study, which was on par with the effectiveness demonstrated in the Multimodal Treatment of Attention Deficit Hyperactivity Disorder (MTA) study (5). As expected, the perceived efficacy was lower when ADHD was comorbid with another diagnosis. Internationally, pharmacological therapy for ADHD has consistently been rated as being less acceptable compared to psychosocial interventions $(16,17)$. However, this was not the case in our study, which could be due to poor effectiveness of nonpharmacological methods in our population. We speculate that doctors having little time to explain psychosocial treatment methods to patients and families in over-crowded clinics, may have played a role in this phenomenon.

Previous work indicates that male gender, older age of the child, lesser severity of ADHD, a family history of ADHD, three times a day dosing and higher education status of the father were associated with the lower adherence $(5,11)$. However, these associations were not seen in this study, which may be due to methodological issues and the number of participants. Skoglund et al., have concluded that higher methylphenidate doses are associated with better long-term treatment adherence in adults with ADHD and substance misuse (18). While we are unable to make a direct comparison with that study, children who had incremental dose increases were more likely to adhere to treatment, compared to those who were on same medication dose for a long period.

Khajehpiri et al., report that all children with ADHD on methylphenidate treatment develop at least one side effect. However, almost half of the children in this study did not complain of side effects. Poor appetite was the most common side effect, which was negatively correlated with poor treatment compliance, most likely due to parental concerns over the child's growth. Evidence suggests that in contrary to early reports that methylphenidate may cause decreased growth rate without evidence of growth rebound, later reviews have concluded that the delay in growth is transient and insignificant $(5,20,21)$.

\section{Limitations}

The fact that this study was conducted among children and teenagers attending one clinic in the Ragama area may limit the generalizability of the findings to the rest of the country.

\section{Conclusions}

The results of this study suggest that methylphenidate is an effective and well-tolerated treatment for children in Sri Lanka with ADHD. Higher rates of adherence to methylphenidate may be due to the high perceived benefits of methylphenidate. However our findings also suggest that treatment providers should pay more attention towards promoting non-pharmacological treatment methods for children with ADHD.

G Jayamaha, WMTM Perera, University Psychiatry Unit, Colombo North Teaching Hospital, Ragama

TA Herath, A Rodrigo, Faculty of Medicine, University of Kelaniya, Ragama

Corresponding author: A Rodrigo

Email: asirir2000@yahoo.com

http://orcid.org/0000-0003-3962-0592

\section{References}

1. Faraone SV, Sergeant J, Gillberg C, Biederman J. The worldwide prevalence of ADHD: Is it an American condition? World Psychiatry. 2003; 2(2): 104-13.

2. Perera H, Jeewandra KC, Jayasuriya N, Dias R. Prevalence of attention deficit hyperactivity disorder in children with unintentional injuries. Sri Lanka Journal of Child Health, 2012; 41(1): 20-3.

3. Biederman J, Faraone SV. Attention-deficit hyperactivity disorder. Lancet 2005; 366(9481): 237-48.

4. Kariyawasam SH, Koralagama A, Jayawardane P, Karunathilake B, Perera V, Perera H. Sri Lanka A descriptive study of attention deficit hyperactivity disorder (ADHD) at Lady Ridgeway Hospital for Children, Colombo. Journal of Child Health, 2002; 31: 109-14.

5. MTA Cooperative Group. A 14-month randomized clinical trial of treatment strategies for attention-deficit/ hyperactivity disorder. Arch Gen Psychiatry. 1999; 56(12): 1073-86.

6. Scheffler RM, Brown TT, Fulton BD, Hinshaw SP, Levine P, Stone S. Positive association between attention-deficit/ hyperactivity disorder medication use and academic achievement during elementary school. Pediatrics. 2009; 123(5): 1273-9. 
7. Matza LS, Stoeckl MN, Shorr JM, Johnston JA. Impact of atomoxetine on health-related quality of life and functional status in patients with ADHD. Expert Rev Pharmacoecon Outcomes Res. 2006; 6(4): 379-90.

8. Powers RL, Marks DJ, Miller CJ, Newcorn JH, Halperin JM. Stimulant treatment in children with attention-deficit/ hyperactivity disorder moderates adolescent academic outcome. Journal of Child and Adolescent Psychopharmacology. 2008; 18(5): 449-59.

9. Wilens TE, Faraone SV, Biederman J, Gunawardene S. Does stimulant therapy of attention-deficit/hyperactivity disorder beget later substance abuse? A meta-analytic review. Pediatrics. 2003; 111(1): 179-85.

10. Hébert J, Polotskaia A, Joober R, Grizenko N. Adherence to psychostimulant medication in children with attentiondeficit/hyperactivity disorder: The role of attitudes. J Can Acad Child Adolesc Psychiatry. 2013; 22(4): 317-23.

11. Gau SS, Shen HY, Chou MC, Tang CS, Chiu YN, Gau CS. Determinants of adherence to methylphenidate and the impact of poor adherence on maternal and family measures. J Child Adolesc Psychopharmacol. 2006; 16(3): 286-97.

12. Faraone SV, Biederman J, Zimmerman B. An analysis of patient adherence to treatment during a 1-year, open-label study of OROS methylphenidate in children with ADHD. Journal of Attention Disorders. 2007; 11(2): 157-66.

13. Shier AC, Reichenbacher T, Ghuman HS, Ghuman JK. Pharmacological treatment of attention deficit hyperactivity disorder in children and adolescents: clinical strategies. J Cent Nerv Syst Dis. 2013; 5: 1-17.

14. Charach A, Ickowicz A, Schachar R. Stimulant treatment over five years: adherence, effectiveness, and adverse effects. J Am Acad Child Adolesc Psychiatry. 2004; 43(5): 559-67.

15. Berger I, Dor T, Nevo Y, Goldzweig G. Attitudes toward attention-deficit hyperactivity disorder (ADHD) treatment: parents' and children's perspectives. J Child Neurol. 2008; 23(9): 1036-42.

16. Johnston C, Hommersen P, Seipp C. Acceptability of behavioral and pharmacological treatments for attentiondeficit/hyperactivity disorder: Relations to child and parent characteristics. Behavior Therapy. 2008; 39(1): 22-32.

17. Krain AL, Kendall PC, Power TJ. The role of treatment acceptability in the initiation of treatment for ADHD. Journal of Attention Disorders. 2005; 9(2): 425-34.

18. Skoglund C, et al. Factors associated with adherence to methylphenidate treatment in adult patients with attention-deficit/hyperactivity disorder and substance use disorders. J Clin Psychopharmacol. 2016; 36(3): 222-28.

19. Khajehpiri Z, Mahmoudi-Gharaei J, Faghihi T, Karimzadeh I, Khalili H, Mohammadi M. Adverse reactions of Methylphenidate in children with attention deficithyperactivity disorder: Report from a referral center. J Res Pharm Pract. 2014; 3(4): 130-6.

20. Faraone S, Biederman J, Morley C, Spencer T. Effect of stimulants on height and weight: a review of the literature. J Am Acad Child Adolesc Psychiatry. 2008; 47(9): 994-1009.

21. Biederman J, Spencer T, Monuteaux M, Faraone S. A naturalistic 10-year prospective study of height and weight in children with attention-deficit hyperactivity disorder grown up: sex and treatment effects. J Pediatr. 2010; 157(4): 635-40. 